\title{
Akut İskemik İnmeli Hastalarda, İnmenin Ciddiyeti İle Monosit/HDL-K Arasındaki İlişki
}

\section{Relationship Between Severity of Stroke and Monocyte / HDL-C in Patients with Acute Ischemic Stroke}

\author{
Ayşegül Demir ${ }^{1 *}$, Fettah Eren ${ }^{1}$ \\ ${ }^{1}$ Sağlık Bilimleri Üniversitesi, Konya Eğitim ve Araştırma Hastanesi, Nöroloji Kliniği, Konya, Türkiye \\ e-mail: D_Raysegul@hotmail.com,dreren42@ hotmail.com \\ ORCID: 0000-0002-5444-9837 \\ ORCID: 0000-0001-6834-0827 \\ *Sorumlu yazar/ Corresponding Author: Ayşegül Demir \\ Gönderim Tarihi / Received: 20.04.2020 \\ Kabul Tarihi / Accepted: 08.06.2020 \\ DOI: $10.34087 /$ cbusbed.723397
}

\section{$\ddot{O} \mathbf{z}$}

Giriş ve Amaç: İnflamasyon ve oksidatif stres, ateroskleroz gelişiminde ve progresyonunda rol oynayan iki önemli faktördür. Monositin yüksek yoğunluklu lipoprotein kolesterole (HDL-K) oranlanmasiyla hesaplanan MHR değerlerinin artışı, inflamasyonda artış ve ateroskleroz gelişiminde hızlanma ile ilişkilendirilmektedir. Bu çalışma ile akut iskemik inme hastalarında inmenin ciddiyeti ve hastane içi ölüm ile MHR değerleri arasındaki ilişkiyi araşstırmayı amaçladik.

Gereç ve Yöntemler: Akut iskemik inme teşhisiyle hastaneye yatırılan ve tedavi edilen 183 hasta retrospektif olarak çalışmaya alındı. Demografik özellikleri, inme risk faktörleri, laboratuvar değerleri ve MHR değerleri kaydedildi. İnmenin ciddiyetini değerlendirmek için National Institutes of Health Stroke Skalası (NIHSS) kullanıldı. Hastane içi ölen hastalar kaydedildi.

Bulgular: Çalışmamızda $82(\% 44,8)$ kadın, $101(\% 55,2)$ erkek olmak üzere toplam 183 hasta vardı. Hastaların yaş ortalaması 68,24 $\pm 14,43$ yıldı. Başvuru NIHSS değerlerine göre $157(\% 85,8)$ hasta ağır disabilite, $26(\% 14,2)$ hasta hafif disabilite grubuna ayrıldı. Ağır başvuru dizabilitesi olan grupta AF sıklı̆̆ı ve MHR değerleri hafif disabilite grubuna göre anlamlı olarak daha yüksekti (sırasıyla $p=0,01, p<0,01$ ). Yine hastane içi ölen hastalarda AF sıklığı ve MHR değerleri taburcu edilen hastalara göre daha yüksekti (sırasıyla p=0,003, p=0,028).

Sonuç: Çalışmamızın sonucunda, inmenin ciddiyeti ve hastane içi ölüm ile artmış MHR değerleri arasında anlamlı ilişki mevcuttu.

Anahtar kelimeler: Dizabilite, İskemik inme, Monosit/HDL-K oranı, Mortalite

\begin{abstract}
Objective: Inflammation and oxidative stress are two important factors that play a role in the development and progression of atherosclerosis. The increase in MHR values calculated by the ratio of monocyte to high density lipoprotein cholesterol (HDL-C) is associated with an increase in inflammation and acceleration in the development of atherosclerosis. We aimed to investigate the severity of stroke in patients with acute ischemic stroke and the relationship between in-hospital death and MHR values with this study.

Materials and Methods: 183 patients hospitalized and treated with the diagnosis of acute ischemic stroke were retrospectively included in the study. Demographic features, stroke risk factors, laboratory parameters, and MHR values were recorded.The National Institutes of Health Stroke Scale (NIHSS) was used to assess the severity of the stroke. Patients who died in hospital were recorded.

Results: In our study, there were 183 patients, $82(44,8 \%)$ female and $101(55,2 \%)$ male. The mean age of the patients was $68.24 \pm 14.43$ years. According to the initial NIHSS values, $157(85,8 \%)$ patients were divided into severe disability, and $26(14,2 \%)$ patients were divided into mild disability. The frequency of AF and MHR were significantly
\end{abstract}


higher in the group with severe disability compared to the mild disability group $(\mathrm{p}=0,01, \mathrm{p}<0,01$, respectively). Also, the frequency of $\mathrm{AF}$ and MHR were higher in patients who died in hospitals compared to the patients discharged ( $\mathrm{p}=0,003, \mathrm{p}=0,028$, respectively).

Conclusion: As a result of our study, there was a significant relationship between the severity of stroke and in-hospital death and increased MHR values.

Keywords: Ischemic stroke, disability, mortality, monocyte/HDL-C ratio.

\section{Giriş}

Akut iskemik inme (Aİi), gelişmiş ülkelerde uzun süreli dizabilitenin önde gelen nedeni olmakla birlikte tüm dünyada en sık ölüm nedenlerinden birisidir. AİI, beynin bir bölgesine ani kan akışının kaybı ve bunun sonucunda ortaya çıkan nörolojik fonksiyon kaybı olarak tanımlanır [1]. Etiyolojik faktörler arasında büyük arter aterosklerozu ve kardiyoembolik nedenler büyük önem taşımaktadır. Kardiyoembolik inmenin en sık nedeni atriyal fibrilasyon (AF)'dur [2]. Ateroskleroz gelişimi ve ilerlemesi patofizyolojisinin ana bileşenleri endotel disfonksiyonu, damar duvarı intima tabakasında lipid ve inflamatuar hücre birikimidir [3,4]. Makrofajlar ve monositler, proinflamatuar sitokinlerin salınmasında anahtar rol oynayan ve inflamasyonun tüm aşamalarına katkıda bulunan hücre tipleridir [2]. Ayrıca monositlerin, trombositler ve endotelyal hücreler ile etkileşime girdiği, pro-trombotik yolakların aktifleşmesine neden olarak vasküler düzeyde aterosklerotik plağın oluşumunda, plağın progresyonunda ve rüptüründe aktif rol oynadığ bilinmektedir [5,6]. Bununla birlikte yüksek yoğunluklu lipoprotein kolesterolün (HDL-K), monosit hücrelerinin aktivasyonunu ve düşük yoğunluklu lipoprotein kolesterol (LDL-K) moleküllerinin oksidasyonunu önleyerek endotel hücrelerini inflamasyondan ve oksidatif stresten koruduğu gösterilmiştir [7]. Antiinflamatuar ve antioksidan etkilerinin yanı sıra, HDL-K molekülleri ayrıca endotelyal nitrik oksit sentaz salınımını artırarak vazorelaksasyona katkı sağlar. Tüm bu verilerin doğrultusunda, monositler proinflamatuar ve prooksidan etki gösterirken, HDL-K bu işlemler sırasında antiinflamatuar ve antioksidan etki gösterir. Artmış Monosit/HDL-K (MHR) oranı, artmış inflamasyonu ve oksidatif stresi göstermektedir [8]. Artmış MHR ile kardiyovasküler hastalıkların ciddiyeti, diyabetik nefropati ve iskemik inmede uzun dönem mortalite ilişkisi gösterilmiştir [2,9,10].

$\mathrm{Bu}$ çalışmada AIİ teşhisi ile kliniğimize yatırılan hastalarda inme ciddiyeti ile MHR değerlerini retrospektif olarak karşılaştırmak ve hastane içi mortalite ile ilişkisini değerlendirmek amaçlanmıştır.

\section{Materyal ve Metot}

$\mathrm{Bu}$ çalışma nöroloji kliniğine AİI teşhisi ile yatırılan hastalarda yapıldı. Çalışma için üniversite hastanesi klinik araştırmalar etik kurulundan (toplantı sayısı: 2019/16 karar sayısı: 2019/352) yerel etik onayı alındı. Çalışmamız, semptomların başlangıcından sonraki ilk 24 saat içinde kliniğimize başvuran 01.01.2020-31.01.2019 arasında AIII tanısı alan 18-90 yaş arası 183 hastayı içeren retrospektif bir çalışmadır. Dosya taramalarında beyin manyetik rezonans görüntülemede veya bilgisayarlı tomografide akut iskemik lezyonları olan ve yatışının ilk 24 saati içinde ayrıntılı nörolojik muayeneleri yapılan (National Institutes of Health Stroke Skalası (NIHSS) hesaplanan) hastalar alındı. Hastaların demografik özellikleri ve inme risk faktörleri kaydedildi. İnme etiyolojisi için bazal elektrokardiyografi (EKG) transtorasik ekokardiyografi (TTE) ve 24 saat holter EKG incelemeleri yapıldı. Hastaların inme başlangıcından itibaren ilk 24 saat içinde alınan kan örneklerinden monosit ve HDL-K seviyeleri kaydedildi. Akut iskemik inme sonrası intravenöz trombolitik tedavi verilen ve endovasküler girişimsel tedavi uygulanan hastalar çalışmaya alınmadı. Akut ve kronik inflamatuar hastalığı olanlar, bağ dokusu hastalığı olanlar, kanser hastaları, ciddi karaciğer ve böbrek yetmezliği olan hastalar ve son 3 ay içinde akut koroner sendrom geçiren hastalar çalışmaya dahil edilmedi. İnme ciddiyetini değerlendirmede National Institutes of Health Stroke Skalası (NIHSS) kullanıldı [11]. Hastalar başvuru NIHSS skoruna göre (NIHSS > 15: ağır dizabilite grubu, NIHSS < 16: hafif dizabilite grubu) iki gruba ayrildı.

Ciddi inmesi olan hastalarla olmayan hastaların ve hastane içi ölen hastalarla taburcu olan hastaların bazal demografik özellikleri, inme risk faktörleri ve kan parametreleri karşılaştırıldı.

\subsection{Kan testleri}

Kan incelemesi için alınan örnekler antekübital venden elde edildi. Semptom başlamasından sonra ilk 24 saat dışındaki hastalardan kan örneği alınmadı. Biyokimyasal tetkikler kuru tüplere, hematolojik tetkikler etilendiamintetraasetik asit (EDTA) lı tüplere konuldu. Tam kan sayımı Mindray BC6800 cihazında Diagon kiti ile biyokimyasal testler ise Beckman Coulter AU5800 cihazında (Beckman Coulter Inc, Hialeah) nefelometrik yöntemle değerlendirildi. Sonuçlardan nötrofil, monosit ve HDL-K seviyeleri değerlendirildi. MHR= monosit/HDL-K formülü kullanılarak hesaplandı.

\subsection{Istatistiksel analiz}

Verilerin analizi için SPSS 16.0 Package software (Statistical Package for the Social Sciences Inc.; Armonk, NY, ABD) analiz programı kullanıldı. Kontrol grubu yoktu. Normallik analizi Kolmogorov-Smirnov testi ile yapıld 1 . Sonuçlar ortalama \pm standart sapma veya ortanca değer (minimum-maksimum) şeklinde ifade edildi. Kategorik veriler sayı ve yüzde olarak belirtildi. Sayısal verilerin karşılaştırılmasında Kruskal Wallis ve Mann Whitney U testi, kategorik verilerin karşılaştırılmasında ki-kare testleri kullanıldı. Sonuçlar \%95'lik güven aralığında, anlamlılık $\mathrm{p}<0,05$ düzeyinde değerlendirildi. 


\section{Bulgular}

Çalışmamızda $82(\% 44,8)$ kadın, $101(\% 55,2)$ erkek olmak üzere toplam 183 hasta vardı. Hastaların yaş ortalaması 68,24 $\pm 14,43$ yıldı. Dizabilite gruplarının bazal demografik özellikleri, inme risk faktörleri ve biyokimyasal parametreleri benzerdi $(\mathrm{p}>0,05)$. Başvuru NIHSS değerleri $157(\% 85,8)$ hastada 16'nın altında, 26 $(\% 14,2)$ hastada 16 ve üzerindeydi. Ağır başvuru dizabilitesi olan grupta AF sıklığı daha fazlaydı $(\mathrm{p}=0,011)$. Bu hastalarda nötrofil ve monosit değerleri daha yüksekti (Nötrofil: 7,42 \pm 4,61 karş1 5,73 $\pm 2,42$; $\mathrm{p}=0,005$ ) (Monosit: $0,70 \pm 0,38$ karşı $0,57 \pm 0,22$; $\mathrm{p}=0,013)$. Yine ağır dizabilitesi olan grupta MHR değeri daha yüksekti $(0,020 \pm 0,012$ karş1 $0,015 \pm 0,007$; $\mathrm{p}=0,009)$ (Tablo 1).

Tablo 1. NIHSS > 15 olan hastalar ile NIHSS $<16$ olan hastaların bazal demografik, hematolojik ve biyokimyasal parametrelerinin karșılaștırılması

\begin{tabular}{|c|c|c|c|}
\hline & NIHSS $<16(n=157)$ & NIHSS > $15(n=26)$ & $\mathbf{P}$ \\
\hline Yaş (y1l) & $67,6 \pm 14$ & $72,4 \pm 16,6$ & 0,11 \\
\hline Kadın, n (\%) & $67(42,7)$ & $15(57,7)$ & 0,202 \\
\hline Diabetes Mellitus, n (\%) & $45(28,7)$ & $4(15,4)$ & 0,231 \\
\hline Hipertansiyon, n (\%) & $110(70,1)$ & $17(65,4)$ & 0,800 \\
\hline Atriyal Fibrilasyon, n (\%) & $43(27,6)$ & $14(53,8)$ & $0,011^{*}$ \\
\hline Sistolik Kan Basınc1 (mmHg) & $140(95-230)$ & $145(90-189)$ & 0,830 \\
\hline Diyastolik Kan Basıncı (mmHg) & $80(55-125)$ & $85(60-130)$ & 0,841 \\
\hline Kreatinin (mg/dl) & $0,90(0,55-2,4)$ & $0,87(0,5-2,0)$ & 0,643 \\
\hline Aspartat Aminotransferaz (u/L) & $20(9-147)$ & $22,5(10-64)$ & 0,070 \\
\hline Total Kolesterol (mg/dL) & $181(82-413)$ & $184,5(114-295)$ & 0,814 \\
\hline Trigliserit (mg/dL) & $117(46-714)$ & $112,5(54-317)$ & 0,780 \\
\hline LDL-K (mg/dL) & $117(41,8-342)$ & $111,1(54,8-219)$ & 0,528 \\
\hline HDL-K (mg/dL) & $38,8 \pm 8,5$ & $39,5 \pm 11,8$ & 0,695 \\
\hline Lökosit sayıs1 (K/uI) & $8,15(3,5-16,78)$ & $8,78(5,56-22,00)$ & 0,193 \\
\hline Hemoglobin (g/dL) & $13,6 \pm 1,9$ & $13,1 \pm 1,9$ & 0,192 \\
\hline Trombosit say1s1 (K/uI) & $240 \pm 66,1$ & $227,3 \pm 72,4$ & 0,369 \\
\hline Nötrofil (K/uI) & $5,73 \pm 2,42$ & $7,42 \pm 4,61$ & $0,005^{*}$ \\
\hline Lenfosit (K/uI) & $2,05 \pm 0,88$ & $1,94 \pm 0,91$ & 0,547 \\
\hline Monosit (K/uI) & $0,57 \pm 0,22$ & $0,70 \pm 0,38$ & $0,013^{*}$ \\
\hline Monosit/HDL-Kolesterol & $0,015 \pm 0,007$ & $0,020 \pm 0,012$ & $0,009^{*}$ \\
\hline
\end{tabular}

HDL-K; Yüksek dansiteli lipoprotein kolesterol, LDL-K; Düşük dansiteli lipoprotein kolesterol, NIHSS; National Institutes of Health Stroke Skala, $\mathrm{n}=$ sayı, $\%=$ yüzde

Hastaların $164(\% 89,6)$ ü taburcu edildi. On dokuz $(\% 10,4)$ hasta yatış süresi içerisinde öldü. Hastane içi ölen hastaların ortalama yaşı $75,5 \pm 12,1$ yıl, taburcu olanların $67,4 \pm 14,5$ yıl idi $(p=0,02)$. Diğer demografik özellikleri, hematolojik ve biyokimyasal parametreleri benzerdi. Hastane içi ölen hastalarda AF sıklığı ve MHR değerleri taburcu edilen hastalara göre daha yüksekti (sirasiyla $\mathrm{p}=0,003 ; \mathrm{p}=0,028)$ (Tablo 2).

\section{Tartışma}

İflamasyon ve oksidatif stres, aterosklerozun gelişiminde ve progresyonunda rol oynayan önemli iki faktördür [8]. İnflamasyon aşamasında dolaşımdaki monositlerden dönüştürülen makrofajlar, aterosklerotik plak oluşumu için anahtar hücre tiplerinden biridir. Monosit aktivasyonu aterosklerotik sürecin başlangıcında çok önemli bir adımdır. Aterosklerotik plak oluşumu sırasında, kan monositleri intima içine alınır ve oksitlenmiş LDL-K ve diğer lipitleri de alarak köpük hücrelerine farklılaşır. Dolayısıyla doku makrofajları ve dolaşımdaki köpük hücrelerinin kaynağı olarak artmış monosit sayısı, yeni aterosklerotik plaklar gelişimi için belirleyici rol oynamaktadır [12]. Daha önce yapılan çalışmalarda yüksek monosit sayılarının koroner arter hastalığı ve AİI gibi aterosklerotik hastalıkların gelişiminde belirleyici olduğu gösterilmiştir $[13,14]$. Kardiyoembolik inmeler için en önemli risk faktörü olan AF patogenezinde de artmış inflamasyonun önemli rol oynadığ 1 gösterilmiştir [15]. Bizim çalışmamızda da yatış NIHSS skoruna göre ciddi inmesi olan hastalarda hafif inmesi olan hastalara göre nötrofil sayıları, monosit sayıları ve AF insidansı anlamlı olarak daha yüksekti. HDL, kolesterolü periferik dokulardan karaciğere geri aktaran ters kolesterol taşınmasından sorumlu lipoproteindir. Antioksidan, antiinflamatuar ve antitrombotik etkileri nedeniyle ateroskleroz gelişiminde önleyici rol almaktadır [16,17,18]. HDL-K'nin endotelyumu LDL-K'nin zararlı etkilerine karşı koruduğu ve LDL-K'nin oksidasyonunu önlediği gösterilmiştir [19]. Ayrıca HDL-K, adezyon moleküllerinin endotelyal salınımını inhibe etmede ve arter duvarına monosit alımını önlemede de oldukça etkilidir [20]. Önceki çalışmalar düşük HDL-K düzeylerinin iskemik inme riskini artırdığını ve inmenin ciddiyeti ile ilişkili olduğunu göstermiştir [21,22]. 
Tablo 2. Hastane içi ölen ve taburcu olan hastaların bazal demografik, hematolojik ve biyokimyasal parametrelerinin karşılaştırılması

\begin{tabular}{|l|c|c|c|}
\hline & Taburcu $(\mathbf{n}=\mathbf{1 6 4})$ & Hastane içi ölüm (n= 19 ) & P \\
\hline Yaş (yıl) & $67,4 \pm 14,5$ & $75,5 \pm 12,1$ & $0,020^{*}$ \\
\hline Kadın, $\mathrm{n}(\%)$ & $70(42,7)$ & $12(63,2)$ & 0,142 \\
\hline Diabetes Mellitus, n (\%) & $45(27,4)$ & $4(21,1)$ & 0,785 \\
\hline Hipertansiyon, n (\%) & $114(69,5)$ & $13(68,4)$ & 0,935 \\
\hline Atriyal Fibrilasyon, n (\%) & $45(27,6)$ & $12(63,2)$ & $0,003^{*}$ \\
\hline Sistolik Kan Basıncı (mmHg) & $140(90-230)$ & $145(105-189)$ & 0,285 \\
\hline Diyastolik Kan Basınc1 (mmHg) & $80(55-130)$ & $85(65-125)$ & 0,581 \\
\hline Kreatinin (mg/dl) & $0,9(0,55-2,4)$ & $0,86(0,50-2,1)$ & 0,602 \\
\hline AST (u/L) & $20(9-147)$ & $23(12-71)$ & 0,014 \\
\hline Total Kolesterol (mg/dL) & $181,5(82-413)$ & $181(107-295)$ & 0,995 \\
\hline Trigliserit (mg/dL) & $117,5(46-714)$ & $105(62-317)$ & 0,410 \\
\hline LDL-Kolesterol (mg/dL) & $115(41,8-342)$ & $110(58-219)$ & 0,828 \\
\hline HDL-Kolesterol (mg/dL) & $38,7 \pm 8,5$ & $40,1 \pm 12,4$ & 0,524 \\
\hline Lökosit sayls1 (K/uI) & $8,2(3,15-17,00)$ & $8,98(5,03-22,00)$ & 0,306 \\
\hline Hemoglobin (g/dL) & $13,6 \pm 1,9$ & $13,3 \pm 1,9$ & 0,538 \\
\hline Trombosit sayls1 (K/uI) & $240 \pm 66,4$ & $223 \pm 72,4$ & 0,300 \\
\hline Nötrofil (K/uI) & $5,77 \pm 2,49$ & $7,66 \pm 4,9$ & $0,006^{*}$ \\
\hline Lenfosit (K/uI) & $2,06 \pm 0,87$ & $1,80 \pm 1,0$ & 0,219 \\
\hline Monosit (K/uI) & $0,57 \pm 0,22$ & $0,73 \pm 0,43$ & $0,090^{*}$ \\
\hline Monosit/HDL-Kolesterol & $0,016 \pm 0,007$ & $0,020 \pm 0,013$ & $0,028^{*}$ \\
\hline
\end{tabular}

HDL-K; Yüksek dansiteli lipoprotein kolesterol, LDL-K; Düşük dansiteli lipoprotein kolesterol, NIHSS; National Institutes of Health Stroke

Skala, $\mathrm{n}=$ sayı, $\%=$ yüzde

Tüm bu veriler sonucunda inflamasyonda önemli rol oynayan monosit ve anti-inflamatuar etkisi olan HDL-K oranlanmasıyla hesaplanan MHR değerlerinin artışı, inflamasyonda artış ve atreoskleroz gelișiminde hızlanma ile ilişkilendirilmektedir. Artmış MHR ile kronik böbrek yetmezliği hastalarında kardiyovasküler hastalık risk artışı, koroner arter hastalığının ciddiyeti, koroner ektazi sıklığı, koroner yavaş akım sıklığ1, kriyoablasyon yapılan hastalarda AF rekürrensi, diyabetik hastalarda nefropati gelişimi ve obstrüktif uyku apneli hastalarda kardiyovasküler olay gelişimi arasındaki ilişki daha önceki çalışmalarda gösterilmiştir $[8,9,10,23,24,25,26]$. Wang ve arkadaşlarının Çin popülasyonunda yaptığı bir kohort çalışmasında artmış MHR'nin iskemik inme gelişiminde prediktif bir faktör olabileceği belirtilmiştir [27]. Bolayır ve arkadaşları akut iskemik inmeli hastalarda MHR değerlerinin kontrol grubuna göre belirgin olarak yüksek olduğunu göstermişler ve aynı zamanda iskemik inmeli hastalarda artmış MHR'nin 30 günlük mortalite için bağımsız bir prediktör olduğunu belirtmişlerdir [2]. Liu ve arkadaşlarının yaptığı 1090 akut iskemik inmeli hastanın dahil edildiği bir çalışmada artmış MHR'nin 3 aylık takipte kötü fonksiyonel iyileşme ile ilişkili olduğu gösterilmiştir [28]. Bizim çalışmamızda AIII teşhisi ile yatırılan hastalarda NIHSS skoruna göre ciddi inmesi olan hastaların MHR değerleri hafif inmesi olan hastalara göre anlamlı olarak yüksekti. Ayrıca taburcu olan hastalara göre hastane içi ölüm görülen hastalarda yine MHR değerleri anlamlı olarak yüksekti.

\section{Sonuç}

Sonuç olarak artmış inflamasyon göstergesi olan MHR değerlerindeki artış, daha önceki çalışmalarda kardiyovasküler ve serebrovasküler hastalıklarla ilişkilendirilmiştir. Bizim çalışmamızın bulguları sonucunda da AIII teşhisi ile yatırılan hastalarda inmenin ciddiyeti ve hastane içi ölümü belirlemede basit bir laboratuvar tetkiki sonucunda hesaplanan MHR değerleri kullanılabileceği görülmüştür. Bu sonucu desteklemek için daha geniş hasta popülasyonu olan çalışmalara ihtiyaç vardır.

\section{Bilgilendirme}

Çalışmayı destekleyen herhangi bir kurum ve kuruluş bulunmamaktadır. Yazarlar arasında çıkar çatışması yoktur.

Bu çalışma, Mart 2020'de (15. Uludağ Nöroloji GünleriBursa) sözel sunum olarak sunulmuştur.

\section{Referanslar}

1.Phipps, M.S, Cronin, C.A, Management of acute ischemic stroke, British Medical Journal, 2020, 368, 16983.

2. Bolayır, A, Gökce, SF et al, Monocyte/high density lipoprotein ratio predicts the mortality in ischemic stroke patients, Neurologia $i$ Neurochirurgia Polskl, 2018, 52(2), 150-55.

3. Schaftenaar, F, Frodermann, V et al, Atherosclerosis, Current Opinion in Lipidology, 2016, 27(3), 209-15.

4.Libby, P, Inflammation in atherosclerosis, Arteriosclerosis, Thrombosis, and Vascular Biology, 2012, 32(9), 2045-51.

5.Mestas, J, Ley, K, Monocyte-endothelial cell interactions in the development of atherosclerosis, Trends in cardiovascular medicine, 2008, 18(6), 228-32.

6. Woollard, KJ, Geissmann, F, Monocytes in atherosclerosis: subsets and functions, Nature Reviews Cardiology, 2010, 7(2), 77-86. 
7.Hafiane, A, Genest, J, High density lipoproteins: Measurement techniques and potential biomarkers of cardiovascular risk, $B B A$ Clinical, 2015, 31(3), 175-88

8. Canpolat, U, Cetin, EH et al, Association of Monocyte-to-HDL Cholesterol Ratio with Slow Coronary Flow is Linked to Systemic Inflammation, Clinical and Applied Thrombosis/Hemostasis, 2016 , 22(5), 476-82.

9. Kundi, H, Kiziltunc, E et al, Association of monocyte/ HDL-C ratio with SYNTAX scores in patients with stable coronary artery disease, Herz,, 2016, 41, 523-9.

10. Onalan, E, The relationship between monocyte to high-density lipoprotein cholesterol ratio and diabetic nephropathy, Pakistan Journal Of Medical Sciences, 2019, 35(4), 1081-6.

11. Brott, T, Adams, H.P Jr et al, Measurements of acute cerebral infarction: a clinical examination scale, Stroke, 1989, 20(7), 864-70.

12. Lambert, J.M, Lopez, E.F et al, Macrophage roles following myocardial infarction, International Journal of Cardiology, 2008, $130(2), 147-58$

13. Choi, S, Kim, J et al, Monocyte count as a predictor of cardiovascular mortality in older Korean people, Age Ageing, 2017, 46(3), 433-8.

14. Grosse, G.M, Schulz-Schaeffer, W.J et al, Monocyte subsets and related chemokines in carotid artery stenosis and ischemic stroke, International Journal of Molecular Sciences , 2016, 17(4), 433.

15. Karabacak, M, Kahraman, F et al, Increased plasma monocyte chemoattractant protein-1 levels in patients with isolated low highdensity lipoprotein cholesterol, Scandinavian Journal of Clinical and Laboratovary Investigation, 2015, 75(4), 327-32.

16. Navab, M, Ananthramaiah, G.M et al, The oxidation hypothesis of atherogenesis: the role of oxidized phospholipids and HDL, Scandinavian Journal of Clinical and Laboratory Investigation, 2004, 45, 993-1007.

17. Barter, PJ, Nicholls, S et al, Antiinflammatory properties of HDL, Circulation Research, 2004, 95, 764-72.

18. Mineo, $\mathrm{C}$, Deguchi, $\mathrm{H}$ et al, Endothelial and antithrombotic actions of HDL, Circulation Research, 2006, 98, 1352-64.

19. Li, X.P, Zhao, S.P et al, Protective effect of high density lipoprotein on endothelium dependent vasodilatation, International Journal of Cardiology, 2000, 73, 231-6.

20. Barter, P.J, Baker, P.W et al, Effect of high-density lipoproteins on the expression of adhesion molecules in endothelial cells, Current Opinion in Lipidology, 2002, 13, 285-8.

21. Sacco, R.L, Benson R.T et al, High-density lipoprotein cholestero and ischemic stroke in the elderly: the Northern Manhattan Stroke Study, Journal of the American Medical Association, 2001, 285, 2729-35

22. Yeh, P.S, Yang, C.M et al, Low levels of high-density lipoprotein cholesterol in patients with atherosclerotic stroke: a prospective cohort study, Atherosclerosis, 2013, 228(2), 472-7.

23. Kanbay, M, Solak, Y et al, Monocyte count/HDL cholesterol ratio and cardiovascular events in patients with chronic kidney disease International Urology and Nephrology, 2014, 46(8), 1619-25.

24. Kundi, H, Gok, M et al, Relationship between monocyte to HDL-C ratio and the severity of isolated coronary artery ectasia, American Journal of Cardiology, 2015, 116(11), 1685-9.

25. Canpolat, U, Aytemir, $\mathrm{K}$ et al, The role of preprocedural monocyteto-high-density lipoprotein ratio in prediction of atrial fibrillation recurrence after cryoballoon-based catheter ablation, Europace, 2015, 17(12), 1807-15

26. Li, N, Ren, L et al, Relationship between monocyte to HDL cholesterol ratio and concomitant cardiovascular disease in Chinese Han patients with obstructive sleep apnea, Cardiovascular Diagnosis and Therapy, 2019, 9(4), 362-370.

27. Wang, H.Y, Shi, W.R et al, Assessing the performance of monocyte to high-density lipoprotein ratio for predicting ischemic stroke: insights from a population-based Chinese cohort, Lipids in Health and Disease, 2009, 18(1), 127.

28. Liu, H, Liu, K et al, Monocyte-to-High-Density Lipoprotein Ratio Predicts the Outcome of Acute Ischemic Stroke, Journal of Atherosclerosis and Thrombosis, 2020, doi: 10.5551/jat.51151.

http://edergi.cbu.edu.tr/ojs/index.php/cbusbed isimli yazarın CBU-SBED başlıklı eseri bu Creative Commons

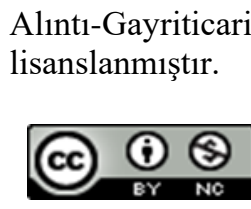

